\title{
Survival and Predictors of Mortality Among Patients Admitted to Intensive Care Unit in Southern Ethiopia: A Multi-center Retrospective Cohort Study
}

semagn Mekonnen Abate ( $\sim$ semmek17@gmail.com )

Department of Anesthesiology, College of Health Sciences and Medicine, Dilla University, Ethiopia https://orcid.org/0000-0001-5661-8537

\section{Sofia Assen}

Dilla University College of Health Sciences

\section{Mengistu Yinges}

Hawassa University College of Medicine and Health Sciences

\section{Bivash Basu}

University of Calcutta

\section{Research}

Keywords: mortality, intensive care unit, hospital, predictor

Posted Date: October 29th, 2020

DOl: https://doi.org/10.21203/rs.3.rs-97694/v1

License: (c) (i) This work is licensed under a Creative Commons Attribution 4.0 International License. Read Full License 


\section{Abstract}

Background: The burden of life-threatening conditions requiring intensive care unit has grown substantially in low-income countries related to an emerging pandemic, urbanization, and hospital expansion. The rate of ICU mortality is varied from region to region in Ethiopia. However, body of evidence on ICU mortality and its predictors is uncertain. This study was designed to investigate the pattern of disease and predictors of mortality in Southern Ethiopia.

Methods: After obtaining Ethical clearance from institutional Review Board (IRB), a multi-center retrospective Cohort study was conducted among three teaching referral hospital ICUs of southern Ethiopia from June, 2018 to May, 2020. Five hundred and seventeen Adult ICU patients were selected. Data were entered in Statistical Package for Social Sciences version 22 and STATA version 16 for analysis. Descriptive statistics were run to see the overall distribution of the variables. Chi square test and odds ratio were determine to identify the association between independent and dependent variables. Multivariate analysis was conducted to control possible confounders and identify independent predictors of ICU mortality.

Results: The mean ( \pm SD) of the patients admitted in ICU was $34.25( \pm 5.25)$. The overall ICU mortality rate was $46.8 \%$. The study identified different independent predictors of mortality. Patients with cardiac arrest were approximately 12 times more likely to die as compared to who didn't, AOR=11.9 (95\% Cl:6.1 to 23.2).

Conclusion: The overall mortality rate in ICU was very high as compared to other studies in Ethiopia as well as globally which entails a rigorous activity from different stakeholders.

\section{Background}

The modern intensive care medicine emerged during the Polio epidemics in the 1950s, which was pioneered by a Danish anesthetist, Bjorn Ibsen at the Kommune hospital of Copenhagen in 1953[1, 2].

The Intensive Care Unit (ICU) is a specially staffed, well equipped, separate, and self-contained area of a hospital dedicated to providing aggressive therapy using state-of-the-art technology and both invasive and noninvasive monitoring for critically ill and high-risk patients[3-6].

The burden of life-threatening conditions requiring management in the intensive care unit has grown substantially in the last couple of decades in low and middle-income countries because of an emerging pandemic, motorization, urbanization, and hospital expansion[7-12]. However, the advancement of ICU care is very limited in these countries due to the high cost of infrastructure, training medical staff, failure to incorporate international guidelines for evidence-based care, and availing medical supplies $[9,11,13-$ 16]. 
Intensive care unit comprises of only 10 percent of hospital bed but it costs more than 30 percent of acute hospital care which is equivalent to 20 percent of the hospital budget and this cost becomes higher in a patient with a severe critical illness which hinders the low resource setting to establish intensive care units[3, 17].

Critical ill patients are admitted to ICU for some reasons including but not limited to respiratory failure, severe infectious diseases, multiple trauma and shock, myocardial infarction, heart failure, renal failure, poisoning, postoperative care, and therapeutic[18-37].

Evidence showed that the incidence of ICU admission ranged from 1 to $54 \%$ globally [17, 35, 37-40]. The cause of ICU admission is not consistent across the globe and the majority of available evidence showed that cardiovascular and respiratory disorders were the commonest causes of admission in middle and high-income countries accounting for 27 to $41 \%$ of admission[17, 35, 37-40] while trauma and postoperative care were the main reasons for ICU admission in low-income countries which varied from 10 to $50 \%[6,37,38,41]$.

Evidence revealed that the outcomes of patients in ICU is greatly related to different factors including but not limited to the pattern of diseases, the severity of the disease, infrastructure, trained medical staff, nursing care, medical supplies, age of patient, presence of comorbidities and multiorgan failure, prehospital and emergency care trauma score, mechanical ventilation, length of ICU stay, complications in ICU, dissemination of antimicrobial-resistant microorganisms and inappropriate or suboptimal use of antibiotics[6, 9, 18, 24-28, 30, 34, 36, 37, 40-48].

The global prevalence of mortality in ICU roughly ranges from 9 to $61 \%$. An international study recruiting 13, 796 participants from Africa, Asia, America, Europe, and Oceania revealed that the prevalence of mortality in ICU was $18.2 \%[49]$.

Other evidence from Sub-Saharan Africa showed that mortality in ICU was ranged from $27 \%$ to $61 \%$ [38, $41,50,51]$. A systematic review and meta-analysis by Vincent et al showed that ICU mortality related to septic shock in Europe and North America was 37.3\% (95\% Cl:35.5 to 43.5\%)[52].

The mortality is very high in the low-income country which is as high as $61 \%$ as compared to developed countries which varied from 9 to $18 \%[28,38,41,50,51,53]$.

The rate of ICU mortality in Ethiopia varied from region to region ranging from 27 to $38 \%[4,6,28,32,46$, 53]. However, the pattern of disease and predictors of mortality in the Southern part of Ethiopia is not well investigated. This multicenter observational study was designed to investigate the pattern of disease and predictors of mortality in selected Southern Ethiopia ICUs.

\section{Materials And Methods}

\section{Study design and setting}


This is a multi-center retrospective observational study conducted in three teaching and referral hospitals in Southern Ethiopia; namely, Hawassa university referral hospital (HURH), Dilla University referral hospital (DURH), and Wolaita Sodo referral hospital (WURH) from June 20, 2018, to May 20, 2020. These teaching and referral hospital ICUs are administered by the Federal Ministry of health and education of Ethiopia. The ICUs are providing a similar level of care with almost similar staff profiles, monitoring modalities, ICU infrastructure, medical supplies, and admission patterns. The care of patients in these ICUs is to the minimum standard because of lack of medical supplies (mechanical ventilator, integrated monitors, vasopressor/inotropes, nutritional support), lack of well-trained staff (lack of intensivist, dentition/nutritionist, physiotherapist). Besides, Dilla University referral hospital, and Wolyta Soso University hospital ICUs didn't have Computerized Tomography (CT), portable chest X-ray Machine, Spirometer, and appropriate Biochemical tests.

\section{Eligibility}

The inclusion criteria for this observational study were all adult patients who were 12 years and above admitted in three of the referral and teaching hospital ICUs during the study period. All patients with incomplete data were excluded.

\section{Variables}

\section{Dependent variables}

The dependent variables were the clinical outcomes in ICU including 30-day mortality, length of ICU stay, the incidence of cardiac arrest, and some days on a mechanical ventilator and complication in ICU

\section{Independent variables}

Socio-demographic characteristics (age and gender), causes of admission, presence of comorbid illness, category of admission, the vital sign at admission, intervention during ICU stay were the independent variables.

\section{Data collection procedures}

The data was collected by three trained bachelors Anesthetist with standardized questionnaire adapted from previous literature $[28,32,36,41,44,49,50,54-56]$. A total of 524 patient charts were recruited from 2119 patients admitted in ICU from June 20, 2018, to 2020 in three hospitals with systematic allocation proportion based on the number of patients admitted during the study period (Fig 1).

The data extraction includes: Socio-demographic characteristics (age of the patient, gender, weight, Height, BMI); Admission variables (admission category, causes of category, vital siggn at admission; intervention in ICU (mechanical ventilation, vasopressor requirement); complication in ICU (cardiac arrest, infection, aspiration) and outcomes (mortality, length of ICU stay and some mechanical ventilator).

\section{Data analysis}


Data will be checked, coded, and entered into Epi-info version 7.0 and imported to SPSS version 22 and STATA version 16 for analysis. Descriptive statistics were summarizing with tables and figures. The categorical variables were reported in Frequency and percentage and the statistical difference was determined by Chi-square and Fisher exact test where appropriate. The numerical data were reported in mean \pm SD for symmetric and median (Interquartile range) for asymmetric numeric data. The outlier of the data will be checked with standardized residual while Shapiro Wilk tests were employed for the normality test. The multi-collinearity among independent variables was checked by Variance inflation factor and tolerance.

Association of demographic characteristics, admission category, causes of admission, and intervention in ICU, a complication in ICU and mortality in ICU was analyzed by using binary logistic regression. The Model fitness was checked using Hosmer-Lemeshow goodness of fitness test, Pseudo R2, and Pearson chi-square statistics. All Variables are significant on bivariate analysis at p-value less than 0.25 were taken to multivariate analysis one after the other to investigate model prediction and independent predictors of the explanatory variables. In multivariate analysis, a p-value of less than 0.05 was considered for the statistical association. This study was conducted in compliance with Strengthening the Reporting of Observational Studies in Epidemiology (STROBE) guidelines for observational studies[57].

\section{Ethical statement}

This study was reviewed and approved by the Institutional Review Board (IRB) of Dilla University and was given a reference number (007/19-10). The study was conducted in compliance with the Helsinki declaration for observational studies. A formal letter was written to each University hospital ICU director to get permission to access the patients' data and all the patient identifiers were kept anonymous.

\section{Results}

A total of 2119 patients were admitted to the three teaching referral Hospitals' ICU from June 2018 to May 2020. Five Hundred and twenty-four patients were selected with systematic proportion allocation from three ICUs. Finally, Five hundred and seventeen were included in the analysis, and the rest seven were excluded due to incomplete data.

\section{Admission characteristics}

The mean $( \pm$ SD) of the patients admitted in ICU was $34.25( \pm 5.25)$. The majority of patients were in the age range of 19 to 39 years while the lowest was in the less than 18 years range. Among 517 patients, the majority $274(53 \%)$ were female while males accounted for $247(47 \%)$.

The majority of Admissions were from emergency department 223(43.1\%) followed by Medical ward 180(34.8\%), gynecology/Obstetrics ward 50(9.7\%) while the lowest were from operation theatre 47(9.1\%) and surgical ward $17(3.3 \%)$. The commonest causes of ICU admissions were acute respiratory distress 
syndrome, Congestive heart failure, and severe pneumonia, stroke, myocardial infarction, and acute kidney injury respectively.

The majority of patients had a respiratory rate greater than twenty breaths per minute while less than twenty-three of patients had respiratory rate less than twelve breaths per minute. Seventy percent of the patients had a pulse rate greater than a hundred beats per minute while only six percent of patients had no palpable pulse at admission.

More than half 272(53.2) of patients had GCS score less than eight while 197(37.1\%) of the patients were hypoxemic $\left(\mathrm{PSO}_{2}\right.$ less than $90 \%$ ) at admission (Table 1).

\section{Table 1 Admission characteristics of patients admitted to Teaching and Referral Hospitals' ICUs in Southern Ethiopia, June 2018 to May 2020.}




\begin{tabular}{|c|c|c|c|c|}
\hline Characteristics & $\begin{array}{l}\text { All admissions } \\
(n=517)\end{array}$ & survivors $(n=275)$ & $\begin{array}{l}\text { Non-survivors } \\
(n=242)\end{array}$ & P-value \\
\hline \multicolumn{5}{|l|}{ Age range (years) } \\
\hline$<18$ & 102(19.7) & $39(35.3)$ & $63(64.7)$ & \\
\hline 19 to 39 & $233(45.1)$ & $117(50.2)$ & $116(49.8)$ & $>0.05$ \\
\hline$>40$ & 182(35.2) & $86(47.3)$ & $96(52.7)$ & \\
\hline \multicolumn{5}{|l|}{ Gender } \\
\hline Female & $274(53.0)$ & $149(54.4)$ & $125(45.6)$ & $>0.05$ \\
\hline Male & $243(47.0)$ & $126(51.9)$ & $117(48.1)$ & \\
\hline \multicolumn{5}{|l|}{ Admission vital sign } \\
\hline \multicolumn{5}{|l|}{ Respiratory rate } \\
\hline$<12$ & $23(4.4)$ & $20(86.9)$ & $3(13.1)$ & \\
\hline 12 to 20 & 119(23.0) & $42(35.3)$ & $77(64.7)$ & $<0.0001^{\star *}$ \\
\hline$>20$ & $375(72.5)$ & $180(48.0)$ & $195(52.0)$ & \\
\hline \multicolumn{5}{|l|}{ Pulse rate } \\
\hline$>100$ & $330(63.8)$ & $169(51.2)$ & $161(48.8)$ & \\
\hline 60 to 100 & $141(27.3)$ & $36(25.5)$ & $105(74.5)$ & $<0.0001^{\star *}$ \\
\hline$<60$ & $13(2.5)$ & $9(69.2)$ & $4(30.8)$ & \\
\hline Not palpable & $33(6.4)$ & $28(84.8)$ & $5(15.2)$ & \\
\hline \multicolumn{5}{|c|}{ Oxygen Saturation (PSO2, \%) } \\
\hline$>90$ & $325(62.9)$ & $184(56.6)$ & $141(43.4)$ & $<0.0001^{\star *}$ \\
\hline$<90$ & 197(37.1) & $58(29.4)$ & 134(70.6) & \\
\hline \multicolumn{5}{|l|}{ Glasgow coma scale } \\
\hline$<8$ & $272(53.2)$ & $184(67.6)$ & $91(32.4)$ & \\
\hline $9-12$ & 196(37.9) & $51(26.0)$ & $145(74.0)$ & $<0.0001^{\star \star *}$ \\
\hline$>12$ & $46(8.9)$ & $7(15.2)$ & $39(84.8)$ & \\
\hline \multicolumn{5}{|l|}{ Sources of admission } \\
\hline Emergency department & $223(43.1)$ & $109(48.9)$ & $114(51.1)$ & \\
\hline Medical ward & $180(34.8)$ & $79(43.9)$ & $101(56.1)$ & \\
\hline Surgical ward & 17(3.3) & $8(47.1)$ & $9(52.9)$ & $>0.05$ \\
\hline
\end{tabular}




\begin{tabular}{|lllll|} 
Gynecology/obstetrics ward & $50(9.7)$ & $21(42.0)$ & $29(58.0)$ & \\
Operation Room & $47(9.1)$ & $25(53.2)$ & $22(46.8)$ & \\
Causes of admission & & & & \\
Myocardial infarction & $33(6.4)$ & $10(30.3)$ & $23(69.7)$ & $0.036^{*}$ \\
Sentic shock & $55(10.6)$ & $21(38.2)$ & $34(61.8)$ & $>0.05$ \\
HIV/AIDS & $30(5.8)$ & $22(73.3)$ & $8(26.7)$ & $0.02^{\star}$ \\
ARDS & $18(3.5)$ & $8(44.4)$ & $10(55.6)$ & $>0.05$ \\
Diabetic ketoacidosis & $57(11.0)$ & $29(50.9)$ & $28(49.1)$ & $>0.05$ \\
stroke & $19(3.7)$ & $7(36.8)$ & $12(63.2)$ & $>0.05$ \\
Acute kidney injury & $40(7.7)$ & $14(35.0)$ & $26(70.0)$ & $>0.05$ \\
Severe Pneumonia & $31(6.0)$ & $16(51.6)$ & $15(48.4)$ & $>0.05$ \\
Others & $45(8.7)$ & $23(51.1)$ & $22(48.9)$ & $>0.05$ \\
& $257(49.7)$ & $112(43.6)$ & $145(56.4)$ & $>0.05$ \\
\hline
\end{tabular}

Note: ** very significant; *significant; ARDS: Acute Respiratory Distress Syndrome; PSO2: percutaneous oxygen saturation

\section{Comorbidity, Intervention, and outcomes}

All Patients admitted to ICU had some comorbidity. The cardiovascular disorders were the commonest comorbidity $183(35.4 \%$ ) followed by respiratory disorders $153(29.6 \%)$, neurologic disorders $133(25.7 \%)$, and infectious disorders 59(11.4\%). However, none of the comorbidities didn't show a significant association with 60 days of mortality $(P>0.05)$. The majority of $278(53.8 \%)$ of patients admitted to ICU were on a mechanical ventilator where $187(67.3 \%)$ of them died during follow up. One-hundred eighty-five patients were on inotropes while 236(45.6\%) of them were on a fluid challenge. All patients admitted to ICU experienced at least one complication during ICU stay. One hundred twenty-five sustained cardiac arrest and 102(81.6\%) of them in time during follow up while $15(2.9 \%)$ had aspiration and from which $11(73.3 \%)$ of them died. The median and IQR of the length of ICU stay was $5(0.2-40)$ days where the minimum and Maximum ICU stays were 4 hours to 40 days respectively. The median survival time for patients with cardiac arrest was approximately seven days as compared to those who didn't where the median time of survival was more than 15 days (Fig 3). The incidence rate of mortality among ICU patients was $46.8 \%$ (Table 2). The mortality of patients in ICU among admission categories was the highest in gynecology/obstetrics followed by other and surgical categories (Fig 2). 
Table 2: prevalence of comorbidities, Intervention, complication, and outcomes of patients admitted to

Teaching Referral Hospitals' ICUs in Southern Ethiopia, June 2018 to May 2020. 


\begin{tabular}{|c|c|c|c|c|}
\hline Characteristics & $\begin{array}{l}\text { All admissions } \\
(n=517)\end{array}$ & survivors ( $n=275)$ & $\begin{array}{l}\text { Non-survivors } \\
(n=242)\end{array}$ & P-value \\
\hline \multicolumn{5}{|l|}{ Comorbidities, n (\%) } \\
\hline Cardiovascular disease & $183(35.4)$ & $97(53.0)$ & $86(47.0)$ & \\
\hline Respiratory disease & 153(29.6) & $79(51.6)$ & $74(48.4)$ & \\
\hline Renal disease & $31(6.0)$ & $15(48.4)$ & 16(51.6) & \\
\hline Infectious disease & $59(11.4)$ & $25(42.4)$ & $34(57.6)$ & $>0.05$ \\
\hline Neurological disease & 133(25.7) & $77(57.9)$ & $56(42.1)$ & \\
\hline Endocrine disease & $29(5.6)$ & $15(51.7)$ & 14(48.3) & \\
\hline Gastrointestinal & $35(6.8)$ & $16(45.7)$ & 19(54.3) & \\
\hline Hematological disease & $27(5.2)$ & $14(51.9)$ & $13(48.1)$ & \\
\hline Rheumatic disease & $5(1.0)$ & $3(60.0)$ & $2(40.0)$ & \\
\hline Others & $30(5.8)$ & $15(50.0)$ & $15(50.0)$ & \\
\hline \multicolumn{5}{|l|}{ Intervention } \\
\hline Mechanical Ventilation & $278(53.8)$ & $91(32.7)$ & 187(67.3) & $<0.0001^{\star *}$ \\
\hline Inotropes & 185(35.8) & $86(46.5)$ & $99(53.5)$ & $0.027 *$ \\
\hline Vasopressors & $274(53.0)$ & $145(52.9)$ & $129(47.1)$ & $>0.05$ \\
\hline Fluid & $236(45.6)$ & $123(25.1)$ & 113(47.9) & $>0.05$ \\
\hline Blood Transfusion & $20(3.9)$ & $8(40.0)$ & $12(60.0)$ & $>0.05$ \\
\hline Feeding & $78(15.1)$ & $38(48.7)$ & $40(51.3)$ & $>0.05$ \\
\hline Surgery & $9(1.7)$ & $5(55.6)$ & $4(44.4)$ & $>0.05$ \\
\hline GIT prophylaxis & $35(6.8)$ & $16(45.7)$ & 19(54.3) & $>0.05$ \\
\hline Antibiotics & $324(62.7)$ & $142(43.8)$ & $51(56.2)$ & $<0.05^{\star}$ \\
\hline others & $248(48.0)$ & $139(56.0)$ & $109(44.0)$ & $<0.0001^{\text {** }}$ \\
\hline \multicolumn{5}{|l|}{ Complications } \\
\hline Cardiac arrest & 125() $24.2)$ & $23(18.4)$ & 102(81.6) & $<0.0001^{\star \star *}$ \\
\hline Anemia & 177(34.2) & $93(52.5)$ & $84(47.5)$ & $>0.05$ \\
\hline Arrhythmia & $43(8.3)$ & $24(55.8)$ & $19(44.2)$ & $>0.05$ \\
\hline Infection & 99019.1 & $44(44.4)$ & $55(55.6)$ & $0.034^{\star}$ \\
\hline
\end{tabular}




\begin{tabular}{|lllll|} 
Hypotension & $332(64.2)$ & $176(53.0)$ & $156(47.0)$ & $>0.05$ \\
Hypertension & $94(18.2)$ & $54(57.4)$ & $40(42.6)$ & $>0.05$ \\
Aspiration & $15(2.9)$ & $4(26.7)$ & $11(73.3)$ & $0.033^{\star}$ \\
\hline
\end{tabular}

Note: ** very significant; *significant; ARDS: Acute Respiratory Distress Syndrome; PSO2: percutaneous oxygen saturation

\section{Determinants of ICU mortality}

The variables showing a p-value of less than 0.25 in bivariate analysis were entered in multivariate analysis with a forward selection method as the explanatory variables were more than fifteen. The model fitness was estimated with Pearson chi-square statistics $\left(X^{2}=282, D F=9, p=0.0001\right)$ and Pseudo $R^{2}=$ 0.561 and insignificant Hosmer -Lemeshow goodness of fit $(p=.412)$. Fifty-six percent of the variation of ICU mortality was explained by the independent variables entered in the final regression model and the rest forty-four percent of the variation may be due to chance or other factors.

The variables that showed a significant difference in multivariate analysis were cardiac arrest, GCS score, aspiration, antibiotic use, mechanical ventilation, hypoxia, infection, and ICU length of stay. The multivariate analysis revealed that Patients who sustained cardiac arrest in ICU were approximately 12 times more likely to die as compared to those who didn't have a cardiac arrest, OR=11.9(95\% confidence interval(Cl): 6.1 to 23.2). The Multivariate analysis also showed that patients whose GCS score less than eight were 8 times more likely to die, OR=8.2(95\% confidence interval(Cl): 2.7 to 25.5) (Table 3).

\section{Table 3: Bivariate and multivariate analysis of 30-days mortality among patients admitted to ICU in Southern Ethiopia Teaching referral hospitals ( $=517), 2020$.}




\begin{tabular}{|c|c|c|c|c|c|}
\hline Variables & $\begin{array}{l}\text { All } \\
\text { admission } \\
(n=517)\end{array}$ & $\begin{array}{l}\text { Survivors } \\
(n=275)\end{array}$ & $\begin{array}{l}\text { Non- } \\
\text { survivors } \\
(n=242)\end{array}$ & $\operatorname{COR}(95 \% \mathrm{Cl})$ & $\operatorname{AOR}(95 \% \mathrm{Cl})$ \\
\hline $\begin{array}{l}\text { Cardiac arrest, } \\
\mathrm{n}(\%)\end{array}$ & $125(24.2)$ & 102(81.6) & $23(18.4)$ & $7.9[4.9,13.1]$ & $\begin{array}{l}\text { 11.9(6.1, } \\
23.2)^{\star \star \star}\end{array}$ \\
\hline Antibiotics(yes), & 192(37.3) & $51(26.4)$ & 142(73.6) & $3.9[2.7,5.9]$ & $\begin{array}{l}5.7(3.2 \\
10.2)^{\star \star \star}\end{array}$ \\
\hline Aspiration(yes) & $15(2.9)$ & 11(73.3) & $4(26.7)$ & $3.2[1.0,10.3]$ & $\begin{array}{l}5.6(1.1 \\
29.4)\end{array}$ \\
\hline Infection(yes) & $99(19.1)$ & $55(55.6)$ & $44(44.4)$ & $1.5[0.9,2.4]$ & $\begin{array}{l}3.1(1.6 \\
5.9)^{\star \star}\end{array}$ \\
\hline MV(yes) & $278(53.8)$ & 187(67.3) & $91(32.7)$ & $6.9[4.6,10.2]$ & $\begin{array}{l}\text { 5.8(3.3, } \\
10.3)^{\star \star \star}\end{array}$ \\
\hline $\begin{array}{l}\text { Hypoxia }\left(\mathrm{PsO}_{2}\right. \\
<90)\end{array}$ & $325(62.9)$ & $184(56.6)$ & $141(43.4)$ & $3.0[2.1,4.4]$ & $1.9(1.1,3.3)$ \\
\hline \multicolumn{6}{|l|}{ GCS } \\
\hline below 8 & $275(53.2)$ & \multirow[t]{2}{*}{$\begin{array}{l}184(66.9) \\
51(26.0)\end{array}$} & & $\begin{array}{l}11.3[4.8,26.2] \\
1.9[0.83,4.7]\end{array}$ & $\begin{array}{l}8.2(2.7 \\
25.5)^{\star \star}\end{array}$ \\
\hline 9 to 12 & 196(37.9) & & $145(74.0)$ & \multirow[t]{2}{*}{ Ref } & \multirow{2}{*}{$\begin{array}{l}1.9(0.6,6.1) \\
\text { Ref }\end{array}$} \\
\hline Above 12 & $46(8.9)$ & $7(37.0)$ & $39(63.0)$ & & \\
\hline $\begin{array}{l}\text { Septic } \\
\text { shock(yes) }\end{array}$ & $30(5.8)$ & $8(26.7)$ & 22(73.3) & $0.3[0.13,0.7]$ & $0.6(0.2,2.0)$ \\
\hline \multicolumn{6}{|l|}{ ICU LOS } \\
\hline$<1$ week & $383(74.1)$ & $202(52.7)$ & $181(47.3)$ & Ref & Ref \\
\hline 1 to 2 weeks & $85(16.4)$ & $27(31.8)$ & $58(68.2)$ & $1.3[0.6,2.8]$ & $1.5(0.6,4.1)$ \\
\hline$>2$ weeks & $49(9.5)$ & $36(73.5)$ & 130 & $3.1[1.6,6.0]$ & $\begin{array}{l}8.7(3.6 \\
20.1)^{\star * \star *}\end{array}$ \\
\hline
\end{tabular}

Note: $* \star *$ : very significant ( $\mathrm{p}$-value $<0.000$; $* *$ : significant ( $\mathrm{p}$-value $<0.0001$ ); ICU LOS: Intensive Care Unit Length of stay; MV: Mechanical Ventilation; $\mathrm{Ps}_{2}$ : Percutaneous Oxygen saturation; Ref: reference; GCS: Glasgow Coma Scale

\section{Discussion}

This multi-center observational study revealed that the majority of patients admitted to ICU were female and younger productive age groups, 19 to 39 years old which are in line with other studies conducted in Sub-Saharan African countries $[6,19,28,32,38,41,46]$. The possible explanation for this difference in 
this age group in low-income countries might be due to engagement in violence, road traffic accident and relatively educated with high health-seeking behavior. On the contrary, the rate of admission to ICU in developed nations was among older patients that might be due to a sedentary lifestyle and high prevalence of the non-communicable disease among these patients [23, 27, 33, 35].

The commonest causes of ICU admissions in our study were cardiovascular and respiratory disorders which are comparable with studies conducted globally $[2,6,20,28,32,45,48,49,52,53,56,58]$. However, there are discrepancies on the causes of admission to intensive care unit where studies conducted in Kenya, Tanzania, Uganda, Nigeria revealed postoperative events were the major causes of Admission[38, 41, 54] while studies were done from Jimma University referral hospital and Addis Ababa Black Lion hospital was due to trauma[46, 53]. An international study from six continents including 10069 patients and another study from Belgium and the UK showed that the major causes of admission were cardiovascular and respiratory disease $[20,40,45]$. This difference may be explained by the types of ICU, level of care of the hospital, types of study design, and socio-demographic characteristics of the population.

This study revealed that the majority of patients were hypotensive, septic, comatose, and hypoxemic with unstable vital signs which were strongly associated with 30-days ICU mortality. In our study, more than fifty percent of patients were on a mechanical ventilator and from which more than sixty percent of died during follow up. This high rate of mortality in patients with mechanical ventilator may be related to a frequent power cut, improper nursing care as they were not trained formally, lack of medication, malnutrition as there was no standard nutrition supplement, and ventilator-associated complications.

The overall ICU mortality rate of this study was higher than studies done in a different region of Ethiopia such as Addis Ababa (39\%), Gondar (38.7\%), Jimma (37.7\%), Mekelle (27\%) $[32,46,59,60]$ and other studies conducted in sub-Saharan Africa namely: Nigeria (34.6\%), Uganda (40.1\%), and Tanzania (41.1\%) $[38,41,61])$. On the other hand, it is lower than studies conducted in Jimma (50.4\%), National Hospital of Abuja (68.4\%), and Burkina Faso 60\% [62-64]. This discrepancy might be due to differences in sample size, level of ICU care, availability of medical supplies, and stratification of skilled staff.

In this study, cardiac arrest, aspiration, being on a mechanical ventilator, hypoxemia at admission and low GCS, and the use of antibiotics and length of stay were independent predictors of mortality. This study revealed that patients who sustained cardiac arrest were approximately 12 times more likely to die as compared to those who didn't, AOR=11.9(95\% Cl:6.1 to 23.2). This high risk of death might be related to inadequate resuscitation drugs and equipment, lack of well-trained staff in advanced cardiac life support (ACLS), inappropriate post-cardiac arrest care, and compliance with ACLS protocol.

The study also revealed that patients with aspiration were 5.6 times more likely to die, AOR $=5.6(95 \% \mathrm{Cl}$ : 1.1. to 29.4) and patients on antibiotics for a prolonged period were still 5.7 times more likely to die as compared to those who didn't have, $A O R=5.7(95 \% \mathrm{Cl}: 3.2$ to 10.2$)$ which was in line with an observational and systematic review $[33,47,65,66]$. The possible explanation might be the rapid emergence and 
dissemination of antimicrobial-resistant microorganisms, administering unnecessary broad-spectrum antibiotics, and undue antibiotics for a prolonged period.

\section{Limitation Of The Study}

This is a multi-center observational study with more than one month follow up and a relatively large sample size. However, this study is not without limitations. The nature of data handling management, unavailability of biochemical tests to determine the severity and prognostic score such as acute physiologic and chronic health evaluation (APACHE), sequential organ failure assessment (SOFA), Simplified Acute Physiology Score (SAPS) was the possible limitations.

\section{Political implication}

This multi-center observational study revealed that the overall mortality rate in ICU was very high as compared to other studies in Ethiopia as well as globally. The main independent predictors of mortality were traced and this entails a rigorous activity from different stakeholders. The majority of predictors could be prevented by availing emergency drugs for management of shock, cardiac arrest, aspiration, intracranial hypertension, arrhythmia, pain management, and sedation; integrative patient monitors as most of the monitors were not functional; training of ICU nurse because most of the nurses didn't have formal intensive care training; provision of adequate calories; availing bedside tests including portable Xray, ultrasound, and biochemical tests.

\section{The implication for further research}

It has been known that retrospective study has its limitations as some important parameters may not be available. Besides, we didn't assess the severity and prognostic scores due to the unavailability of biochemical tests in some centers. Therefore, a multi-center prospective cohort study is in demand.

\section{Conclusion}

The overall ICU mortality rate was very high. The majority of independent predictors were cardiac arrest, aspiration, infection, unstable vital signs at admission, and being on a mechanical ventilator which could be minimized by implementing appropriate ICU care with a set of guidelines and protocols.

\section{Abbreviations}

APACHE: Acute Physiologic and Chronic Health Evaluation; AOR: Adjusted Odds Ratio; ACLS: advanced cardiac life support; ARDS: Acute Respiratory Distress Syndrome; BMI: Body Mass Index; Cl: Confidence Interval; CT: Computerized Tomography; DURH: Dilla University referral hospital; GCS: Glasgow Coma Scale; HURH: Hawassa university referral hospital; ICU: Intensive Care Unit; IRB: Institutional Review 
Board; IQR: Inter Quartile e Range; LOS: Length of Stay; SAPS: Simplified Acute Physiology Score; SD:

Standard Deviation; SOFA: Sequential Organ Failure Assessment; STROBE: Strengthening the Reporting of Observational Studies in Epidemiology; WURH: Wolaita Sodo referral hospital

\section{Declarations}

\section{Ethics approval and consent to participate}

Ethical clearance and approval were obtained from the ethical review board of the College of Health Science and Medicine.

\section{Consent for publication}

Not applicable

\section{Availability of data and materials}

Data and material can be available where appropriate.

\section{Competing interests}

The authors declare that there are no competing interests

\section{Funding}

This research was funded a total of USD 833 by Dilla University postgraduate program.

\section{Authors' contribution}

MY conceived the idea, design the research, and collect the data. SA and SA perform the analysis and supervise the research project. All authors read and approved the final manuscript

\section{Acknowledgements}

The authors would like to acknowledge Dilla University for financial and technical support encouragement to carry out the project.

\section{References}


1. Berthelsen $P$, Cronqvist M. The first intensive care unit in the world: Copenhagen 1953. Acta Anaesthesiologica Scandinavica. 2003;47(10):1190-5.

2. Okafor U. Challenges in critical care services in Sub-Saharan Africa: perspectives from Nigeria. Indian Journal of Critical Care Medicine: Peer-reviewed, Official Publication of Indian Society of Critical Care Medicine. 2009;13(1):25.

3. Brilli RJ, Spevetz A, Branson RD, Campbell GM, Cohen H, Dasta JF, et al. Critical care delivery in the intensive care unit: defining clinical roles and the best practice model. Critical care medicine. 2001;29(10):2007-19.

4. Haftu $\mathrm{H}$, Hailu T, Medhaniye A. Assessment of pattern and treatment outcome of patients admitted to the pediatric intensive care unit, Ayder Referral Hospital, Tigray, Ethiopia, 2015. BMC research notes. 2018;11(1):1-6.

5. Marshall JC, Bosco L, Adhikari NK, Connolly B, Diaz JV, Dorman T, et al. What is an intensive care unit? A report of the task force of the World Federation of Societies of Intensive and Critical Care Medicine. Journal of critical care. 2017;37:270-6.

6. Obsa MS, Adem AO, Gete GB. Clinical outcomes of patients admitted in intensive care units of Nigist Eleni Mohammed Memorial Hospital of Hosanna, Southern Ethiopia. International Journal of Medicine and Medical Sciences. 2017;9(6):79-85.

7. Adhikari NK, Fowler RA, Bhagwanjee S, Rubenfeld GD. Critical care and the global burden of critical illness in adults. The Lancet. 2010;376(9749):1339-46.

8. Baker T. Critical care in low-income countries. Tropical Medicine \& International Health. 2009;14(2):143-8.

9. Firth $\mathrm{P}, \mathrm{T}$ tendo $\mathrm{S}$. Intensive care in low-income countries-a critical need. N Engl J Med. 2012;367(21):1974-6.

10. Fowler RA, Adhikari NK, Bhagwanjee S. Clinical review: critical care in the global context-disparities in the burden of illness, access, and economics. Critical Care. 2008;12(5):225.

11. Murthy S, Leligdowicz A, Adhikari NK. Intensive care unit capacity in low-income countries: a systematic review. PloS one. 2015;10(1):e0116949.

12. Razzak JA, Hyder AA, Akhtar T, Khan M, Khan UR. Assessing emergency medical care in low-income countries: a pilot study from Pakistan. BMC emergency medicine. 2008;8(1):8.

13. Dondorp A, Dünser M, Schultz M. Infrastructure and Organization of Adult Intensive Care Units in Resource-Limited Settings-Sepsis Management in Resource-limited Settings. 2019.

14. Papali A, Adhikari NK, Diaz JV, Dondorp AM, Dünser MW, Jacob ST, et al. Infrastructure and Organization of Adult Intensive Care Units in Resource-Limited Settings. Sepsis Management in Resource-limited Settings: Springer, Cham; 2019. p. 31-68.

15. Tumukunde J, Sendagire C, Ttendo SS. Development of Intensive Care in Low-Resource Regions. Current Anesthesiology Reports. 2019;9(1):15-7. 
16. Arabi YM, Schultz MJ, Salluh JI. Intensive Care Medicine in 2050: global perspectives. Springer; 2017.

17. Rosenberg AL, Watts $C$. Patients readmitted to ICUs: a systematic review of risk factors and outcomes. Chest. 2000;118(2):492-502.

18. Abhulimhen-lyoha BI, Pooboni SK, Vuppali NKK. Morbidity pattern and outcome of patients admitted to a pediatric intensive care unit in India. Indian Journal of Clinical Medicine. 2014;5:IJCM. S13902.

19. Agalu A, Woldie M, Ayele Y, Bedada W. Reasons for admission and mortalities following admissions in the intensive care unit of a specialized hospital, in Ethiopia. International Journal of Medicine and Medical Sciences. 2014;6(9):195-200.

20. Arulkumaran N, Harrison D, Brett S. Association between day and time of admission to critical care and acute hospital outcome for unplanned admissions to adult general critical care units: cohort study exploring the 'weekend effect'. BJA: British Journal of Anaesthesia. 2017;118(1):112-22.

21. Auld S, Caridi-Scheible M, Blum JM, Robichaux CJ, Kraft CS, Jacob JT, et al. ICU and ventilator mortality among critically ill adults with COVID-19. medRxiv. 2020.

22. Bellani G, Laffey JG, Pham T, Fan E, Brochard L, Esteban A, et al. Epidemiology, patterns of care, and mortality for patients with acute respiratory distress syndrome in intensive care units in 50 countries. Jama. 2016;315(8):788-800.

23. Cardoso LT, Grion CM, Matsuo T, Anami EH, Kauss IA, Seko L, et al. Impact of delayed admission to intensive care units on mortality of critically ill patients: a cohort study. Critical care. 2011;15(1):1-8.

24. Chen Y-C, Lin S-F, Liu C-J, Jiang DD-S, Yang P-C, Chang S-C. Risk factors for ICU mortality in critically ill patients. Journal-Formosan Medical Association. 2001;100(10):656-61.

25. Depuydt PO, Vandijck DM, Bekaert MA, Decruyenaere JM, Blot SI, Vogelaers DP, et al. Determinants and impact of multidrug antibiotic resistance in pathogens causing ventilator-associatedpneumonia. Critical Care. 2008;12(6): R142.

26. Fowler RA, Sabur N, Li P, Juurlink DN, Pinto R, Hladunewich MA, et al. Sex-and age-based differences in the delivery and outcomes of critical care. Cmaj. 2007;177(12):1513-9.

27. Gayat E, Cariou A, Deye N, Vieillard-Baron A, Jaber S, Damoisel C, et al. Determinants of long-term outcome in ICU survivors: results from the FROG-ICU study. Critical care. 2018;22(1):8.

28. Gidey K, Hailu A, Bayray A. PATTERN AND OUTCOME OF MEDICAL INTENSIVE CARE UNIT ADMISSIONS TO AYDER COMPREHENSIVE SPECIALIZED HOSPITAL IN TIGRAY, ETHIOPIA. Ethiopian Medical Journal. 2017;56.

29. Groenland CN, Termorshuizen F, Rietdijk WJ, van den Brule J, Dongelmans DA, de Jonge E, et al. Emergency department to ICU time is associated with hospital mortality: A registry analysis of 14,788 patients from six university hospitals in the Netherlands. Critical care medicine. 2019;47(11):1564.

30. Khalil MM, Salem HM, El Tohamy MF. Characteristics and clinical outcome of patients treated in the respiratory ICU of Abbassia Chest Hospital. Egyptian Journal of Bronchology. 2019;13(1):93. 
31. Knaus WA, Wagner DP, Zimmerman JE, Draper EA. Variations in mortality and length of stay in intensive care units. Annals of Internal Medicine. 1993;118(10):753-61.

32. Lema G, Tessema H, Mesfin N, Fentie D, Arefaynie N. Admission pattern, Clinical outcomes and associated factors among patients admitted in the medical intensive care unit at University of Gondar Comprehensive and specialized hospital, Northwest Ethiopia, 2019. A retrospective crosssectional study. 2019.

33. Liang C-A, Lin Y-C, Lu P-L, Chen H-C, Chang H-L, Sheu C-C. Antibiotic strategies and clinical outcomes in critically ill patients with pneumonia caused by carbapenem-resistant Acinetobacter baumannii. Clinical Microbiology and Infection. 2018;24(8):908. e1-. e7.

34. Mendez-Tellez PA, Dorman T, editors. Predicting patient outcomes, futility, and resource utilization in the intensive care unit: the role of severity scoring systems and general outcome prediction models. Mayo Clinic Proceedings; 2005: Elsevier.

35. Moran JL, Bristow P, Solomon PJ, George C, Hart GK, Australian, et al. Mortality and length-of-stay outcomes, 1993-2003, in the binational Australian and New Zealand intensive care adult patient database. Critical care medicine. 2008;36(1):46-61.

36. Ongóndi M, Mwachiro M, Ranketi S. Predictors of mortality in a critical care unit in southwestern Kenya. Annals of African Surgery. 2016;13(1).

37. Onyekwulu F, Anya S. Pattern of admission and outcome of patients admitted into the Intensive Care Unit of University of Nigeria Teaching Hospital Enugu: A 5-year review. Nigerian Journal of Clinical Practice. 2015;18(6):775-9.

38. Sawe HR, Mfinanga JA, Lidenge SJ, Mpondo BC, Msangi S, Lugazia E, et al. Disease patterns and clinical outcomes of patients admitted in intensive care units of tertiary referral hospitals of Tanzania. BMC international health and human rights. 2014;14(1):26.

39. Sjoding MW, Prescott HC, Wunsch H, Iwashyna TJ, Cooke CR. Longitudinal changes in intensive care unit admissions among elderly patients in the United States. Critical care medicine. 2016;44(7):1353.

40. Vincent J-L, Marshall JC, Ñamendys-Silva SA, François B, Martin-Loeches I, Lipman J, et al. Assessment of the worldwide burden of critical illness: the intensive care over nations (ICON) audit. Lancet Respiratory Medicine. 2014;2(5):380-6.

41. Ilori IU, Kalu QN. Intensive care admissions and outcome at the University of Calabar Teaching Hospital, Nigeria. Journal of critical care. 2012;27(1):105. e1-. e4.

42. Diaz JV, Riviello ED, Papali A, Adhikari NK, Ferreira JC. Global critical care: moving forward in resource-limited settings. Annals of global health. 2019;85(1).

43. Lone NI, Gillies MA, Haddow C, Dobbie R, Rowan KM, Wild SH, et al. Five-year mortality and hospital costs associated with surviving intensive care. American journal of respiratory and critical care medicine. 2016;194(2):198-208.

44. Murthy S, Adhikari NK. Global health care of the critically ill in low-resource settings. Annals of the American Thoracic Society. 2013;10(5):509-13. 
45. Sakr Y, Moreira CL, Rhodes A, Ferguson ND, Kleinpell R, Pickkers P, et al. The impact of hospital and ICU organizational factors on outcome in critically ill patients: results from the Extended Prevalence of Infection in Intensive Care study. Critical care medicine. 2015;43(3):519-26.

46. Smith Z, Ayele Y, McDonald P. Outcomes in critical care delivery at Jimma University Specialised Hospital, Ethiopia. Anesthesia and intensive care. 2013;41(3):363-8.

47. Paul M, Shani V, Muchtar E, Kariv G, Robenshtok E, Leibovici L. Systematic review and meta-analysis of the efficacy of appropriate empiric antibiotic therapy for sepsis. Antimicrobial agents and chemotherapy. 2010;54(11):4851-63.

48. Navarrete-Navarro P, Rivera-Fernández R, López-Mutuberría MT, Galindo I, Murillo F, Dominguez JM, et al. Outcome prediction in terms of functional disability and mortality at 1 year among ICUadmitted severe stroke patients: a prospective epidemiological study in the south of the European Union (Evascan Project, Andalusia, Spain). Intensive care medicine. 2003;29(8):1237-44.

49. Vincent J-L, Rello J, Marshall J, Silva E, Anzueto A, Martin CD, et al. International study of the prevalence and outcomes of infection in intensive care units. Jama. 2009;302(21):2323-9.

50. Dünser M, Towey R, Amito J, Mer M. Intensive care medicine in rural sub-Saharan Africa. Anesthesia. 2017;72(2):181-9.

51. Henry O, Amata A. A Two-year Review of Admissions to the Intensive Care Unit of the Georgetown Public Hospital Corporation, Guyana. West Indian Med J. 2017;66(6):628.

52. Vincent J-L, Jones G, David S, Olariu E, Cadwell KK. Frequency and mortality of septic shock in Europe and North America: a systematic review and meta-analysis. Critical Care. 2019;23(1):1-11.

53. Haile S. One Year Retrospective Review of Disease Patterns and Clinical Outcomes of Patients Admitted in Intensive Care Units of Armed Force General Teaching Hospital in Addis Ababa, Ethiopia: Addis Ababa University; 2014.

54. Lalani HS, Waweru-Siika W, Mwogi T, Kituyi P, Egger JR, Park LP, et al. Intensive care outcomes and mortality prediction at a national referral hospital in Western Kenya. Annals of the American Thoracic Society. 2018;15(11):1336-43.

55. Riviello ED, Kiviri W, Fowler RA, Mueller A, Novack V, Banner-Goodspeed VM, et al. Predicting mortality in low-income country ICUs: the Rwanda Mortality Probability Model (R-MPM). PloS one. 2016;11(5):e0155858.

56. Tomlinson J, Haac B, Kadyaudzu C, Lee C, Muyco A, Charles A. 205: CRITICAL CARE IN SUBSAHARAN AFRICA: OUTCOMES IN THE MIDST OF AUSTERITY. Critical Care Medicine. 2011;39(12):52.

57. Von Elm E, Altman DG, Egger M, Pocock SJ, Gøtzsche PC, Vandenbroucke JP, et al. The Strengthening the Reporting of Observational Studies in Epidemiology (STROBE) Statement: guidelines for reporting observational studies. International journal of surgery. 2014;12(12):1495-9.

58. Melaku Z, Alemayehu M, Oli K, Tizazu G. Pattern of admissions to the medical intensive care unit of Addis Ababa University Teaching Hospital. Ethiop Med J. 2006;44(1):33-42. 
59. Bayisa T, Berhane A, Kedir S, Wuletaw T. ADMISSION PATTERNS AND OUTCOMES IN THE MEDICAL INTENSIVE CARE UNIT OF ST. PAUL'S HOSPITAL MILLENNIUM MEDICAL COLLEGE, ADDIS ABABA, ETHIOPIA. Ethiopian medical journal. 2017;55(1).

60. Gidey K, Hailu A, Bayray A. Pattern and outcome of medical intensive care unit admissions to ayder comprehensive specialized hospital in Tigray, Ethiopia. Ethiopian Medical Journal. 2018;56(1).

61. Kwizera A, Dünser M, Nakibuuka J. National intensive care unit bed capacity and ICU patient characteristics in a low-income country. BMC research notes. 2012;5(1):475.

62. Agalu A, Mirkuzie W, Ayele Y, Bedada W. Reasons for admission and mortalities following admissions in the intensive care unit of a specialized hospital, Ethiopia. Int J Med Med Sci. 2014;6(9):195-200.

63. Ohaegbulam S, Okafor U, Ihekire O, Elumelu E. Using the Revised Trauma Score to Predict Outcome in Severely Head Injured Patients in a Developing Nation-A Pilot Study. International Journal of Medicine and Health Development. 2007;12(2):51-5.

64. Dao B, Rouamba A, Ouedraogo D, Kambou T, Bazié A. Transfer of obstetric patients in a pregnant and postpartum condition to an intensive care unit: eighty-two cases in Burkina Faso. Gynecologie, obstetric \& fertility. 2003;31(2):123-6.

65. Luyt C-E, Bréchot N, Trouillet J-L, Chastre J. Antibiotic stewardship in the intensive care unit. Critical care. 2014;18(5):480.

66. Roberts JA, Paul SK, Akova M, Bassetti M, De Waele JJ, Dimopoulos G, et al. DALI: defining antibiotic levels in intensive care unit patients: are current $\beta$-lactam antibiotic doses sufficient for critically ill patients? Clinical infectious diseases. 2014;58(8):1072-83.

\section{Figures}




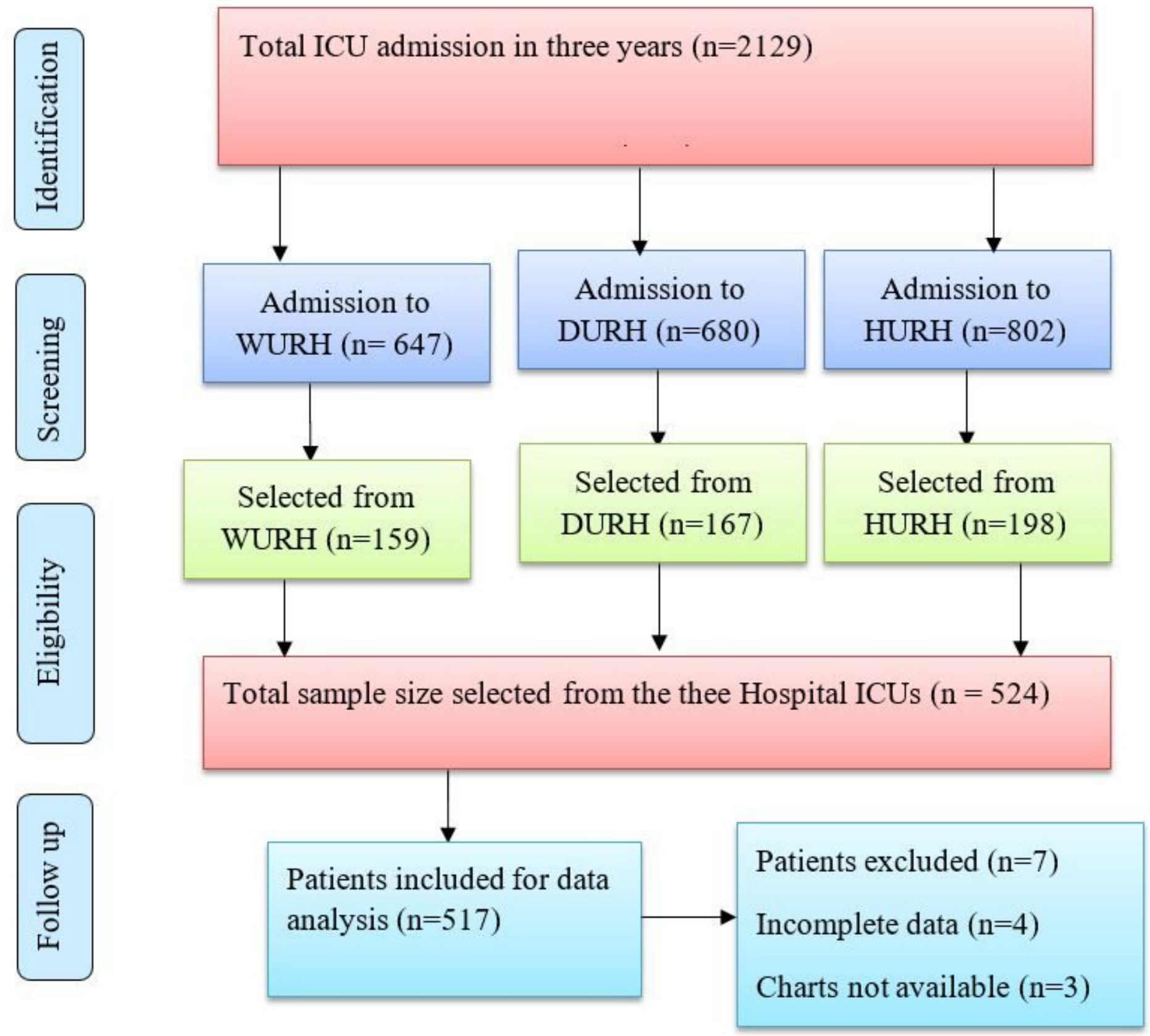

Figure 1

strobe flow chart 


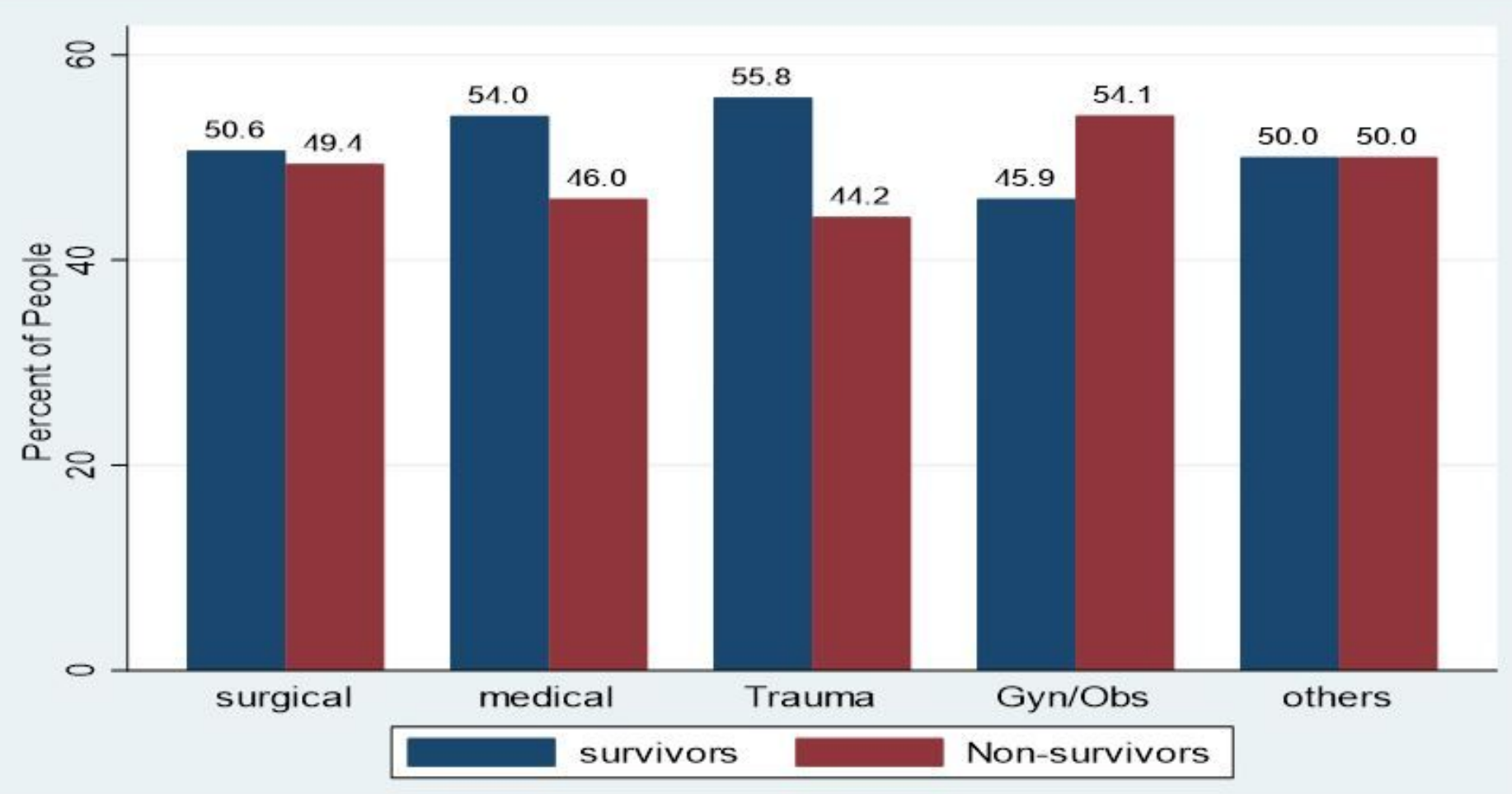

Figure 2

Mortality by category of admission in Southern Ethiopia Teaching and Referral Hospitals' ICU from June 2018 to May 2020.

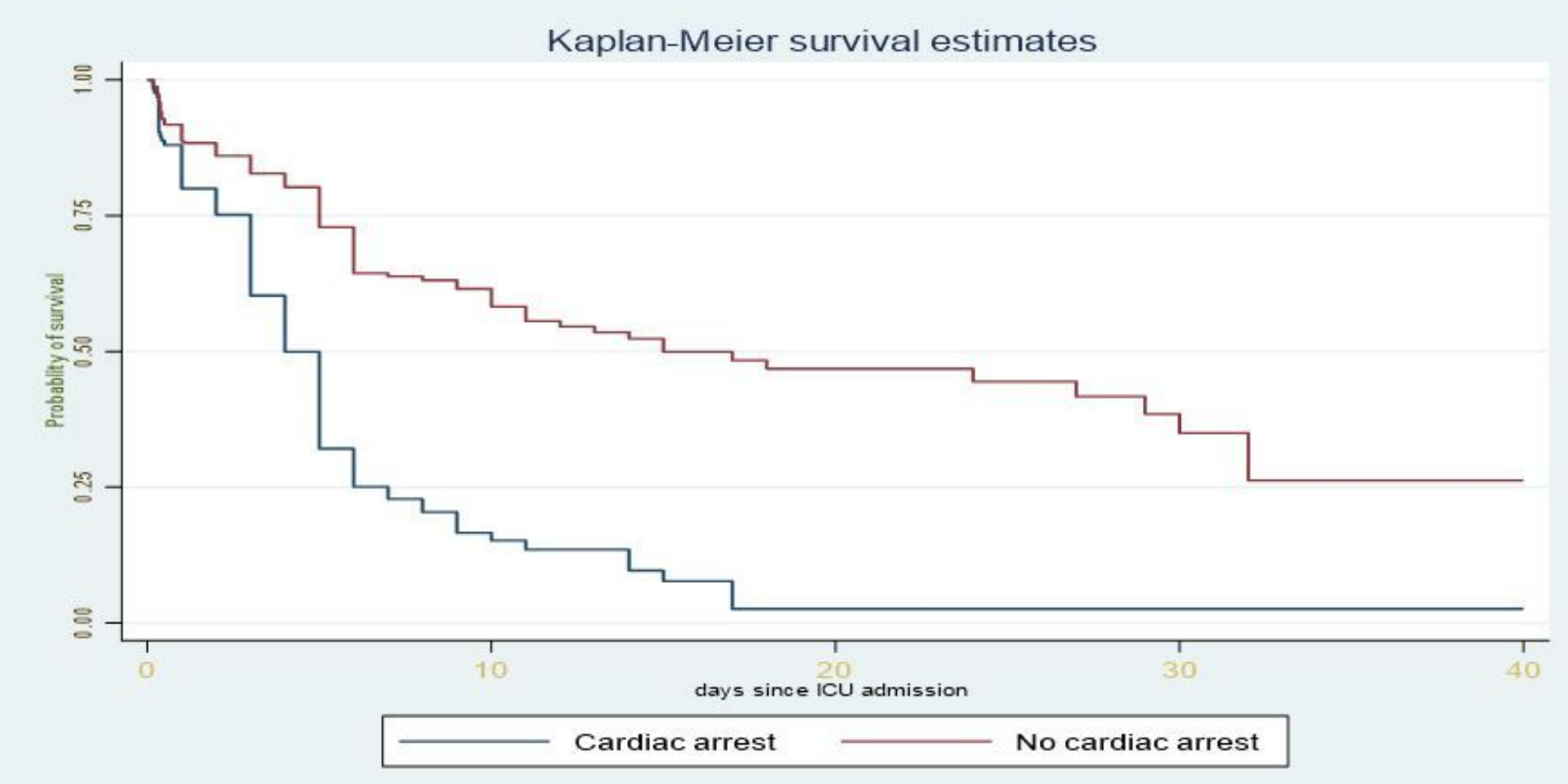

Figure 3 
Kaplan Meier survival plot on the influence of Cardiac arrest on 30-days survival during ICU stay 